\title{
PERBANDINGAN INFORMASI CITRA ANTARA SEQUENCES T2 FAST FIELD ECHO DAN SUSCEPTIBILITY WEIGHTED IMAGING PADA PEMERIKSAAN MRI BRAIN IRISAN AXIAL DENGAN KASUS MICROBLEEDS
}

\author{
${ }^{1}$ Afandi, ${ }^{2}$ Luthfi Rusyadi, ${ }^{3}$ Fatimah, ${ }^{4}$ Jeffry Ardiyanto \\ 1), 2), 3), 4) Jurusan Teknik Radiodiagnostik dan Radioterapi Poltekkes Kemenkes Semarang \\ e-mail: afandi_funz@yahoo.com
}

\begin{abstract}
Background : The Gradient echo sequence is a sequence using RF excitation pulse varied and with flip NMV through various angle (Instead of $90^{\circ}$ ). It's sensitive in detecting the present of hemorrhages that have susceptibility and blooming effect to hemorrhages. T2 fast field echo (T2 FFE) and susceptibility weighted imaging (SWI) are part of the gradient echo pulse sequences, in which T2 FFE sequences is conventional nonsteady state imaging 2D milti-slice and SWI is 3D velocity compensated sequence gradient echo. On both the sequence is very good for asses the hemorrhages particularly microbleeds. This study aims to determine differences in image information and determine the most optimal image information between T2 FFE and SWI sequences in brain MRI axial slices with microbleeds cases.

Methods : Type of research is quantitative experimental approach. The data was taken from October to November 2016 at Radiology Installation of Siloam Hospital Lippo Village. The study populations was all examinations brain MRI with the microbleeds cases, 5 samples with inclusion criteria described. Scanning by using T2 FFE and SWI sequences, then evaluation by respondents furthermore the data was processed using kappa test, and analyzing the date using wilcoxon test, and then to get an assesment of the most optimal images seen from the mean rank wilcoxon test.
\end{abstract}

Results : The result was p-value 0,025 ( $\mathrm{p}<0,05)$ means that Ho refused and Ha accepted, so that statistically showed significant differences at images information between T2 FFE and SWI sequences in examinations brain MRI axial slices with microbleeds case, with mean rank on SWI sequence is 3, and mean rank on T2 FFE is 0, so it's can be concluded that SWI sequence produces a better images information on the examination brain MRI axial slices with microbleeds cases than T2 FFE sequence.

Conclusion : there is a difference of images information between T2 FFE and SWI sequences in Brain MRI axial slices with microbleeds cases, and SWI sequences produces a better images information on the Brain MRI axial slices with microbleeds cases.

Keywords : Image information, T2 FFE, SWI, Microbleeds

\section{Pendahuluan}

Otak (Brain) merupakan organ vital yang bertanggung jawab atas fungsi mental dan intelektual. Otak terdiri dari sel-sel otak yang disebut neuron.
Jaringan otak dibungkus oleh selaput otak dan tulang tengkorak yang kuat dan terletak dalam cavum cranii. Otak dibungkus oleh tiga selaput otak (Meningen) dan dilindungi oleh tulang tengkorak. Otak mengapung 
dalam suatu cairan untuk menunjang otak yang lembek dan halus. Cairan ini bekerja sebagai penyerap goncangan akibat pukulan dari luar terhadap kepala (Syaihuddin, 2011).

Otak juga merupakan organ tubuh yang bekerja terus menerus tentu membutuhkan suplai darah yang cukup dan teraliri secara kontinyu agar fungsi otak berlangsung dengan baik. Dalam keadaan fisiologis jumlah darah yang dikirim ke otak (Blood flow cerebral) adalah kira-kira 20 persen cardiac out-put atau kira-kira 1100-1200 cc permenit untuk seluruh jaringan otak yang berat normalnya kira-kira 2 persen dari berat badan orang dewasa (Irianto, 2014).

Pembuluh darah otak rentan terjadinya kerusakan yang menyebabkan terjadinya pendarahan, Penyebab utama yang paling sering adalah hipertensi, Cerebral amyloid angiopathy (CAA), serta faktor usia juga sangat berpengaruh terhadap peningkatan resiko terjadinya pendarahan. Cerebral microbleeds merupakan kelainan dari pembuluh darah otak yang disebabkan oleh pendarahan otak kronis kecil yang kemungkinan disebabkan oleh kelainan struktur. Cerebral microbleeds dapat di temukan pada cerebrovascular disease, dementia, dan pasien normal yang berusia lanjut. berbagai ukuran digunakan untuk membedakan antara microbleeds dan macrobleeds, biasanya microbleeds berkisar hingga diameter maksimum 5-10 $\mathrm{mm}$ dan minimal $2 \mathrm{~mm}$ (Ramirez, 2014).

Bukti yang berkembang mengidentifikasikan bahwa microbleeds merupakan penanda rentannya terjadi pendarahan angiopati, peningkatan perkembangan hemorrhage, dan peningkatan resiko stroke dimasa depan, sehingga sangat penting untuk mengentahui adanya microbleeds (Kakar, 2016).

Magnetic Resonance Imaging (MRI) merupakan modalitas pencitraan yang paling sensitif dalam mendiagnosis kelainan intrakranial. MRI dapat melukiskan anatomi dengan detail yang sangat baik dan dapat memperlihatkan akurasi yang jauh lebih baik. Anatomi vascular juga dapat divisualisasikan tanpa bantuan kontras intravena dan hal ini telah menurunkan jumlah prosedur vascular invasif. MRI dapat mendemostrasikan otak dengan menggunakan fasilitas multiplanar pada bidang axial, koronal, dan sagital dengan gambaran yang sangat baik pada fossa posterior, karena tidak terdapat artefact tulang (Patel, 2005).

Pada pemeriksaan MRI, sequences dipilih berdasarkan kasus dan objek yang ingin diperiksa. Microbleeds merupakan salah satu kasus pendarahan yang sangat cocok dengan menggunakan pulse sequences gradient echo, dimana sequences Gradient echo merupakan kelas pulse sequence yang digunakan untuk scanning cepat yang banyak digunakan dalam 3D Volume imaging dan aplikasi yang membutuhkan kecepatan akuisisi. Gradient echo juga disebut Gradient-recalled echo, Gradient-refocused echoes, dan field echo. Istilah Field echo mengacu pada magnetic field yang dihasilkan oleh gelombang frequency-encoding gadient yang rephases gradient echo. Gradient echo mempunyai flip angle yang kecil yang memungkinkan TR bernilai sangat pendek, sehingga waktu scan dapat diturunkan (Bernstein dkk, 2004).

Pulse sequences Gradient Echo sensitif dalam mendeteksi pendarahan khususnya microbleeds, yang memiliki efek susceptibility dan blooming terhadap pendarahan. Susceptibility Weighted Imaging (SWI) dan T2 Fast Field Echo (FFE) merupakan bagian dari pulse sequences gradient echo. (Ramirez, 2014). Menurut Mittal S (2009) Susceptibility weighted imaging (SWI) merupakan fully velocity compensated high-resolution $3 D$ gradient echo sequence yang menggunakan informasi magnitude, dan filteredphase, baik secara terpisah maupun dalam kombinasi satu sama lain untuk membuat sumber kontras terbaru. SWI memiliki kontras yang unik yang berbeda dari atenuasi spin, T1, T2, dan T2*. SWI menggunakan perbedaan susceptibility antara jaringan untuk menghasilkan kontras, sequence gradient echo dengan long TE digunakan dan sinyal dari jaringan dengan perbedaan magnetic susceptibility menjadi out of phase. Efek phase ini digunakan untuk menghasilkan kontras citra (Westbrook, 2011). Sedangkan T2 Fast field echo (FFE) sama dengan Sequence T2* Weighted yang memberikan kontras T2-Weighted Gradient echo 2D multi-slice. Istilah T2 FFE hanya di MRI merk Philips dengan menggunakan Flip angle yang kecil, dan sangat sensitif terhadap pendarahan khususnya microbleeds.

Tujuan dari penelitian ini adalah untuk mengetahui perbedaan informasi citra dan mengetahui informasi citra yang paling optimal antara sequences T2 FFE dan SWI pada pemeriksaan MRI Brain irisan axial dengan kasus microbleeds.

\section{Metode}

Jenis penelitian ini adalah penelitian kuantitatif dengan pendekatan eksperimen yang bertujuan untuk membandingkan informasi citra yang dihasilkan antara Sequences T2 FFE dan SWI pada pemeriksaan MRI Brain Irisan Axial dengan kasus Microbleeds.

Pengambilan sampel pada penelitian ini menggunakan Purposive sampling yang berdasarkan kriteria yang telah ditetapkan, baik kriteria inklusi 
maupun eksklusi. Peneliti menggunakan 5 sampel pasien yang melakukan pemeriksaan MRI Brain dengan kasus Microbleeds di Instalasi Radiologi Siloam Hospital Lippo Village Tangerang. kriteria inklusi yang digunakan yaitu: 1) Pasien yang bersedia menjalani pemeriksaan dan mengikuti jalannya penelitian, 2) Pasien yang tidak mengalami claustrophobia, 3) Pasien yang berusia $\geq 55$ tahun. Responden pada penelitian ini adalah 3 dokter spesialis radiologi yang memiliki kompetensi dan berpengalaman $\geq 5$ tahun dalam memberikan ekspertisi MRI.

Prosedur dalam penelitian ini adalah:

1. Tahap persiapan yang meliputi persiapan pemeriksaan dan registrasi data pasien

2. Tahap pelaksanaan yang meliputi posisi pasien, pengaturan sequences dan parameter

3. Penilaian informasi citra oleh 3 responden, adapaun informasi citra yang dinilai adalah microbleeds, vasculars, dan artefact.

4. Penilaian yang dilakukan responden dengan memberikan tanda check list $(\sqrt{ })$ pada kuesioner yang telah disediakan. Pemberian nilai dilakukan pada daerah microbleeds, dan vasculars yaitu dengan cara memberikan skor, yaitu: skor 3 berarti "sangat jelas", skor 2 berarti "cukup jelas", dan skor 1 berarti "tidak jelas". Sedangkan pemberian nilai pada artefact yaitu dengan cara pemberian skor yaitu: skor 1 diberikan apabila "ada artefact", dan skor 2 diberikan apabila "tidak ada artefact".

5. Setelah data terkumpul dari hasil kuesioner tersebut lalu diolah dengan cara membuat tabel skor menurut masing-masing citra yang dinilai dari ketiga responden

6. Kemudian skor tersebut dirata-ratakan berdasarkan penilaian ketiga responden tersebut.

Data diolah dan dianalisis menggunakan program SPSS 16.0. Data yang didapat berupa data ordinal dan berpasangan. Terlebih dahulu dilakukan uji kappa pada responden yang mengisi kuesioner penelitian, analisis data dilakukan dengan uji Wilcoxon-Signed Rank Test untuk menilai ada tidaknya perbedaan yang signifikan dengan tingkat kemaknaan 95\%. Untuk menilai informasi citra yang paling optimal dapat dilihat pada Mean rank yang tertera pada hasil pengujian Wilcoxon-Signed Rank Test.

\section{Hasil dan Pembahasan}

Penelitian ini merupakan perbandingan informasi citra antara sequences T2 FFE dan SWI pada pemeriksaan MRI Brain irisan axial dengan kasus microbleeds yang dilakukan di Instalasi Radiologi MRI 3 Tesla Siloam Hospital Lippo Village Tangerang. Penelitian ini menggunakan sampel 5 pasien dengan usia $\geq 55$ tahun.

Tabel 1. Deskripsi sampel berdasarkan usia

\begin{tabular}{ccccc}
\hline & N & Minimum & Maximum & Msean \\
\hline Usia Pasien & 5 & 56 & 72 & 63,80 \\
\hline
\end{tabular}

Berdasarkan tabel 1 Jumlah sampel yang digunakan dalam penelitian adalah 5 sampel dengan usia minimal 56 tahun, dan usia maksimal yaitu 72 tahun dengan rata-rata usia yaitu 64 tahun.

Penelitian ini menggunakan 3 responden (dokter spesialis radiologi) dalam melakukan penilaian informasi citra pada sequence T2 FFE dan sequence SWI dengan masa kerja \pm 5-7 tahun, yang terdiri 1 responden laki-laki, dan 2 responden perempuan.

Hasil penelitian diperoleh dari penilaian informasi citra pada sequence T2 FFE dan sequence SWI. Hasil citra berupa irisan axial dengan mengambil 4 irisan pada masing-masing sequences yang menunjukan adanya microbleeds. Berikut gambar 1. merupakan hasil citra dari sequence T2 FFE dan sequence SWI, yaitu sebagai berikut:

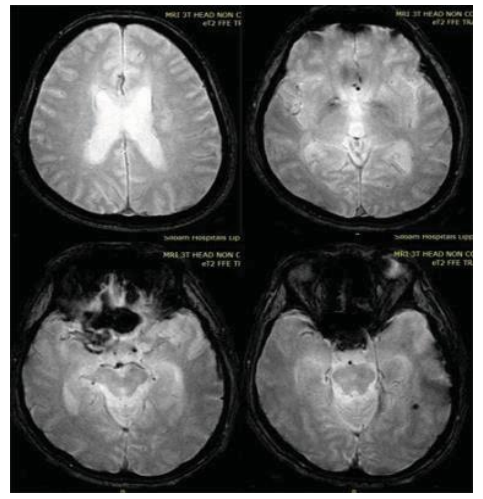

(A) 


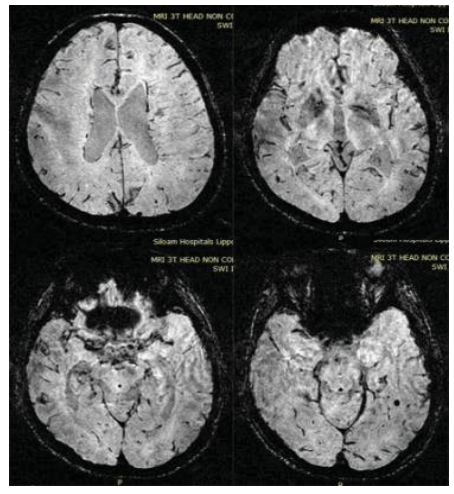

(B)

Gambar 1. Citra sequence T2 FFE (A), dan citra

sequence SWI (B) pada kasus microbleeds

Deskripsi hasil penelitian diambil dari salah satu penulaian responden yang telah dilakukan uji konsistensi cohen's kappa. Uji konsistensi Cohens Kappa merupakan ukuran yang menyatakan konsistensi pengukuran yang dilakukan dua orang penilai (Rater) atau konsistensi antar dua metode pengukuran atau dapat juga mengukur konsistensi antar dua alat pengukuran. Koefisien Cohen's Kappa hanya diterapkan pada hasil pengukuran data kategorik. Berikut tabel 2 tentang hasil uji satistik Kappa, sebagai berikut:

Tabel 2. Hasil uji statistik Kappa

\begin{tabular}{cccc}
\hline No. & Uji & Value & Keterangan \\
\hline 1. & Kappa & 0,875 & Reliabilitas baik \\
\hline
\end{tabular}

Berdasarkan hasil dari uji Kappa di atas dapat diketahui bahwa nilai Kappa sebesar 0,8 maka dapat dikatakan responden mempunyai reliabilitas yang baik (minimal Kappa $=0,8$ ) yang artinya terdapat kesepakatan yang signifikan antara masing-masing Responden, sehingga peneliti hanya mendeskripsikan hasil penelitian dari salah satu responden.

Berikut tabel 3 tentang nilai informasi citra yang diperoleh dari nilai microbleeds dan vasculars pada sequence T2 FFE dan sequence SWI, yaitu sebagai berikut:

Tabel 3. Nilai informasi citra pada sequences T2 FFE dan sequence SWI

\begin{tabular}{lllllllllll}
\hline & \multicolumn{1}{c}{ Informasi citra T2FFE } & \multicolumn{1}{c}{ Informasi citra SWI } \\
\hline Sampel & 1 & 2 & 3 & 4 & 5 & 1 & 2 & 3 & 4 & 5 \\
\hline Nilai & 5 & 5 & 5 & 5 & 5 & 6 & 6 & 6 & 6 & 6 \\
\hline
\end{tabular}

Tabel 3 merupakan nilai yang diperoleh dari penilaian responden terhadap informasi citra
MRI Brain irisan axial pada sequence T2 FFE dan sequence SWI yang diambil dari nilai microbleeds dan vasculars. Pada sequence T2 FFE nilai informasi citra dari sampel 1-5 adalah 5, dan pada sequence SWI nilai informasi citra dari sampel 1-5 adalah 6. Berdasarkan nilai informasi citra antara kedua sequences tersebut terdapat selisih nilai yaitu pada sequence T2 FFE nilai terendah dan tertinggi adalah 5, sedangkan pada sequence SWI nilai terendah dan tertinggi adalah 6, maka diantara kedua sequences tersebut sequence SWI terbaik.

Berikut tabel 4. tentang nilai informasi citra berdasarkan kriteria pada sequence T2 FFE dan sequence SWI, yaitu sebagai berikut:

Tabel 4. Nilai informasi citra berdasarkan kriteria anatomi pada sequences T2 FFE dan SWI

\begin{tabular}{cccc}
\hline No & $\begin{array}{c}\text { Kriteria } \\
\text { Anatomi }\end{array}$ & $\begin{array}{c}\text { Skor penilaian } \\
\text { sequence T2 } \\
\text { FFE }\end{array}$ & $\begin{array}{c}\text { Skor penilaian } \\
\text { sequence SWI }\end{array}$ \\
\hline 1 & Microbleeds & 15 & 15 \\
\hline 2 & Vascular & 10 & 15 \\
\hline & Jumlah & 25 & 30 \\
\hline
\end{tabular}

Tabel 4 merupakan hasil penilaian yang diperoleh dari penilaian responden terhadap informasi citra MRI Brain irisan axial berdasarkan kriteria anatomi dengan 5 sampel. Pada sequence T2 FFE diperoleh nilai Microbleeds $=15$, Vasculars $=10$, dan jumlah totalnya adalah 25, sedangkan pada sequence SWI diperoleh nilai Microbleeds $=15$, Vasculars $=15$, dan jumlah totalnya adalah 30 . Berdasarkan nilai pada tabel 4 nilai berdasarkan kriteria anatomi yang didapatkan dari penilaian responden, jika dilihat pada sequence T2 FFE jumlah nilai untuk informasi anatomi microbleeds dan vasculars adalah 25 , sedangkan pada sequence SWI. jumlah nilai untuk informasi anatomi microbleeds dan vasculars adalah 30, jika dilihat dari nilai kedua sequences tersebut maka sequence T2 FFE dan sequence SWI baik dalam memperlihatkan microbleeds, sedangkan untuk vasculars lebih baik pada sequence SWI.

Nilai artefact diperoleh dari penilaian responden terhadap hasil citra dengan keterangan ada atau tidak adanya artefact pada hasil citra sequence T2 FFE dan sequence SWI, keterangan penilaian adalah nilai 2 (tidak ada artefact), dan nilai 1 (ada artefact). Berikut tabel 5 tentang nilai artefact pada hasil citra sequence T2 FFE dan sequence SWI, yaitu sebagai berikut:

Tabel 5. Nilai artefact pada hasil citra sequence T2 FFE dan sequence SWI 


\begin{tabular}{ccccccccccc}
\hline & \multicolumn{3}{c}{$\begin{array}{c}\text { Nilai artefact } \\
\text { pada T2FFE }\end{array}$} & \multicolumn{4}{c}{$\begin{array}{c}\text { Nilai artefact } \\
\text { pada SWI }\end{array}$} \\
\hline Sampel & 1 & 2 & 3 & 4 & 5 & 1 & 2 & 3 & 4 & 5 \\
Nilai & 2 & 2 & 2 & 2 & 2 & 1 & 1 & 2 & 1 & 2 \\
\hline
\end{tabular}

Tabel 5. merupakan nilai yang diperoleh dari penilaian responden terhadap artefact pada hasil citra sequence T2 FFE dan sequence SWI. Pada sequence T2 FFE dari sampel 1-5 diperoleh nilai 2 yang berarti "tidak ada artefact", sedangkan pada sequence SWI sampel 1, 2, dan 4 diperoleh nilai 1 yang berarti "ada artefact", dan sampel 3 dan 5 diperoleh nilai 2 yang berarti "tidak ada artefact".

Setelah semua data hasil penelitian dideskripsikan pada tabel diatas, pengolahan selanjutnya yaitu menggunakan uji statistik sebagai data penguat adanya perbedaan diatas. Pengujiannnya menggunakan uji wilcoxon karena data yang dihasilkan berupa data ordinal dan berpasangan. Uji Wilcoxon terhadap informasi citra anatomi secara keseluruhan yang meliputi microbleeds dan vasculars. Berikut tabel 4.6 tentang hasil uji wilcoxon terhadap informasi citra anatomi secara keseluruhan, yaitu sebagai berikut:

Tabel 6. Hasil uji Wilcoxon terhadap informasi citra anatomi secara keseluruhan

\begin{tabular}{|c|c|c|c|c|c|}
\hline \multirow[b]{2}{*}{ No } & \multirow[b]{2}{*}{ Uji } & \multirow{2}{*}{$\begin{array}{c}\mathrm{p}- \\
\text { Value }\end{array}$} & \multicolumn{2}{|c|}{ Mean Rank } & \multirow[b]{2}{*}{ Keterangan } \\
\hline & & & $\begin{array}{r}\mathrm{T} 2 \\
\mathrm{FFE}\end{array}$ & SWI & \\
\hline 1. & Wilcoxon & 0,025 & 0 & 3 & $\begin{array}{l}\text { Perbedaan } \\
\text { signifikan }\end{array}$ \\
\hline
\end{tabular}

Berdasarkan hasil uji statistic non parametrik Wilcoxon diatas menunjukkan nilai signifikan $p$ value $=0.025$ atau $\mathrm{p}<0.05$ artinya Ho ditolak dan $\mathrm{Ha}$ diterima, sehingga secara statistik menunjukkan adanya perbedaan yang signifikan pada informasi citra anatomi antara sequence T2 FFE dan sequence SWI pada pemeriksaan MRI Brain irisan axial.

Berdasarkan nilai Mean Rank pada uji wilcoxon untuk sequence T2 FFE adalah 0, dan sequence SWI adalah 3, Hal ini menunjukkan bahwa sequence SWI pada pemeriksaan MRI Brain menghasilkan informasi anatomi yang lebih baik.

Berdasarkan hasil pengujian menggunakan Uji Wilcoxon terhadap informasi citra anatomi secara keseluruhan yang meliputi microbleeds dan vasculars dengan $p$-value 0,025 dapat disimpulkan bahwa Ho ditolak dan Ha diterima maka ada perbedaan informasi citra antara sequences T2 FFE dan SWI pada pemeriksaan MRI Brain irisan axial dengan kasus microbleeds.

Hasil citra microbleeds pada gradient echo berbentuk seperti lesi bulat hypointens kecil. Microbleeds merupakan endapan kecil dari hasil degradasi darah yang terdapat didalam makrofag dan berhubungan dengan struktur vasculars abnormal (Kakar, 2012). Sequence gradient echo sensitif terhadap efek susceptibility yang dapat memaksimalkan efek paramagnetik dari komponen darah seperti hemosiderin, deoxyhemoglobin, dan feritin yang disebabkan oleh dephasing sinyal MRI, sequences gradient echo cenderung untuk membesarkan ukuran lesi, oleh karena itu microbleeds sub-milimeter akan tampak seperti lesi signal-loss dengan beberapa milimeter, hal ini disebut dengan efek blooming (Kim, 2013).

Sequence T2 FFE dan sequence SWI termasuk kedalam sequence gradient echo, dimana kedua sequences ini sensitif terhadap efek magnetic susceptibility. Magnetic susceptibility adalah kemampuan suatu zat menjadi magnet, perbedaan magnetik jaringan pada perbedaan derajat yang menghasilkan perbedaan precessional frequency dan phase, hal ini menyebabkan dephasing pada interface jaringan dan signal loss (Westbrooks, 2011).

Sequence SWI diperoleh dengan threedimensional, velocity compensated sequence gradient echo yang mengacu pada penggunaan magnitude dan phase image atau gabungan dari keduanya, Kontras pada citra SWI sangat berbeda dari citra T1-weighted, T1-weighted contrast enhanced, T2-weighted, diffusion, perfusion, atau angiographic. (Vivek, 2005). Akuisisi three-dimensional volumetric memperoleh data dari seluruh volume jaringan dan bukan dengan pemisahan slice, banyak slice yang bisa diperoleh (biasanya 128-256). Sequence SWI tidak menggunakan slice gap dan volume citra yang dihasilkan dapat memperlihatkan ukuran lesi yang kecil karena slice thickness yang digunakan kecil, secara umum waktu scanning relatif lama sehingga memungkinkan resiko artefact yang disebabkan oleh pergerakan yang disebut dengan phase mismapping atau ghosting. Waktu scanning dipengaruhi oleh TR, NEX, jumlah phase encoding, dan jumlah slice encoding.

Sequence T2 FFE disebut juga dengan T2* Weighted karena pengaruh medan magnet inhomogen dan medan magnet homogen yang sempurna tidak bisa dihasilkan karena efek susceptibility. Sequence T2 FFE merupakan bentuk konvensional non-steady steate imaging dengan TR yang cepat dan flip angle eksitasi kecil. Untuk mendapatkan citra sequence T2 FFE maka perbedaan waktu T2* dari jaringan dimaksimalkan dan perbedaan waktu T1 diminimalkan. Sequence T2 FFE dalam bentuk 2D 
multi-slice dan memiliki slice gap. Pada sequence ini diperoleh waktu scanning yang pendek yang dipengaruhi oleh TR, NEX, dan jumlah phase encoding.

Pada sequence SWI menghasilkan informasi citra anatomi microbleeds sangat jelas yaitu berbatastegas, hypointense, kecil, dan bulat serta pada vasculars sangat jelas yaitu berbatas tegas dan hypointense sedangkan pada sequence T2 FFE menghasilkan citra anatomi microbleeds sangat jelas yaitu berbatastegas, hypointense, kecil, dan bulat serta pada vasculars cukup jelas yaitu tidak berbatas tegas, dan hypointense dimana citra anatomi vasculars tampak lebih jelas pada SWI dibandingkan pada T2 FFE. Pada sequence SWI memungkinkan adanya artefact akibat pergerakan (Phase mismapping/ ghosting) lebih besar dibandingkan dengan sequence T2 FFE karena sequence SWI memiliki waktu scanning yang relatif lama. Penelitian ini hanya membahas tentang perbedaan informasi citra yang dihasilkan antara sequence T2 FFE dan sequence SWI, dan belum dilakukan penelitian tentang waktu scanning.

Berdasarkan nilai Mean Rank pada uji wilcoxon terhadap informasi citra anatomi secara keseluruhan yang meliputi microbleeds dan vasculars diperoleh nilai mean rank pada sequence SWI adalah 3, sedangkan pada sequence T2 FFE nilai mean rank adalah 0 , hal ini menunjukkan bahwa sequence SWI pada pemeriksaan MRI Brain menghasilkan informasi anatomi yang lebih optimal dibandingkan dengan sequence T2 FFE. Sequence SWI menggunakan proses akuisisi three-dimensional yang memungkinkan penggunaan slice thickness yang kecil tanpa gap sehingga dapat meningkatkan resolusi citra, dan dapat menginterpretasikan microbleeds dan vasculars kecil dengan sangat baik. Sequence SWI menggunakan long TE (time echo) yang memungkinkan untuk lebih dephasing antara jaringan dengan perbedaan suceptibility sehingga menyebabkan peningkatan efek blooming yang memungkinkan lesi kecil akan terlihat lebih besar dan jelas.

\section{Simpulan}

Terdapat perbedaan informasi citra yang signifikan antara sequences T2 FFE dan SWI pada pemeriksaan MRI Brain irisan axial dengan kasus microbleeds dengan $\mathrm{p}$-value $0,025(\mathrm{p}<0,05)$ pada hasil uji wilcoxon.

Berdasarkan nilai mean rank pada hasil uji wilcoxon dapat disimpulkan bahwa sequence SWI menghasilkan informasi citra yang lebih baik dari pada sequence T2 FFE pada pemeriksaan MRI Brain irisan axial dengan kasus microbleeds

\section{Daftar Pustaka}

Berstein, Matt A, dkk, 2004, MRI Pulse Sequences, USA : Elsevier Academic Press.

Cheng, Ah-Ling, dkk, 2013, Susceptibility Weighted Imaging is More Reliable Than T2*Weighted Gradient-Recalled Echo MRI For Detecting Microbleeds, http://stroke.ahajournals.org/content/stro kea ha/ (diakses 25 Juli 2016)

Dahlan, M, Supiyudin, 2014, Statistik Untuk Kesehatan: Deskriptif, Bivariat, dan Multivariat, Dilengkapi Aplikasi dengan Menggunakan SPSS, Jakarta : Epidemiologi Indenesia

Donal W, Mc Robble, dkk, 2006, MRI from Picture to Proton, New York : Cambridge University Press.

Govin B, dkk, 2009, Principles, Techniques, and Applications of T2*-Based MR Imaging and Its Special Applications. http://pubs.rsna.org. (diakses 25 Juli 2016).

Irianto Koes, 2014, Anatomi dan Fisiologi, Bandung : Alfabeta.

Kakar, Puneet, dkk, 2012, Cerebral Microbleeds : A New Dilemma In Stroke Medicine, https://www.ncbi.nlm.nih.gov/pmc/ $\begin{array}{lll}\text { articles/PMC3738371/ } & \text { (diakses } & 18\end{array}$ September 2016)

Kim, Beom Joon, dan Seung-Hoon Lee, 2013, Cerebral Microbleeds : Their Associated Factors, Radiologic Finding, And Clinical Aplication.

https://www.ncbi.nlm.nih.gov/pmc/articles/ PMC3859003/ (diakses 18 September 2018) 
Mittal S, Z.Wu, J. Neelavalli, E.M. Haacke, 2009, Susceptibility Weighted Imaging: Technical Aspects and Clinical

Applications http://www.ajnr.org/content/30/2/232.full. (Diakses 18 September 2016) Monica Ester. Jakarta : EGC.

Patel, Pradip R, 2007, Lecture Notes Radiologi, Jakarta : Erlangga

Ramirez, Sergi Martinez dkk, 2014, Cerebral Microbleeds: Overview and Implications in cognitive impairment.

https://www.ncbi.nlm.nih.gov/ (diakses 18 September 2016)

Sajith, Manah, 2014, Anatomy of Cerebellum, In Slideshare, Health \& Medicine, Technology.

Setiadi, 2007, Konsep dan Penulisan Riset Keperawatan, Yogyakarta : Graha Ilmu

Syaihuddin, 2011, Anatomi Fisiologi Buku Kedokteran, Alih Bahasa Indonesia

Vivek, Seghal, dkk, 2005, Clinical Applications of Neuroimaging With Susceptibility Weighted Imaging. https://www.ncbi.nlm.nih.gov/ (diakses 18 September 2016)

Westbrook, Catherine, Carolyn Kaut, dan John Talbot, 2011, MRI in Practice, Fourth Edition, United Kingdom : Blackwell Science Ltd.

Westbrook, Chaterine, 2008, Handbook of MRI Technique, Third Edition, United Kingdom : Blackwell Science Ltd. 